\title{
Removal of Some Heavy Metals from Wastewater by Using of Fava Beans
}

\author{
Abdunnaser Mohamed Etorki, Mahmoud El-Rais, Mohamed Tahher Mahabbis, \\ Nayef Mohamed Moussa \\ Department of Chemistry, University of Tripoli, Tripoli, Libya \\ Email: a.etorki@yahoo.com
}

Received 29 December 2013; revised 3 February 2014; accepted 11 February 2014

Copyright @ 2014 by authors and Scientific Research Publishing Inc.

This work is licensed under the Creative Commons Attribution International License (CC BY). http://creativecommons.org/licenses/by/4.0/

(c) (i) Open Access

\section{Abstract}

The Fava Beans were used in this work as low cost adsorbent material for removal of $\mathrm{Pb}$ (II), Cd(II) and $\mathrm{Zn}$ (II) ions from aqueous solutions. The samples were prepared without farther treatment and sorted according to the particles diameter by standard sieves $250-500 \mu \mathrm{m}$. Batch adsorption experiments were carried out to study the adsorption process, several parameters such as Initial pH of adsorbent, effect of contact time, effect of adsorbent amount and effect of metal concentration were conducted in these experiments. The effects of any one of those previously mentioned parameters on the adsorption capacity were studied while the other parameters were kept constant. It was found that the obtained maximum adsorption capacities of Fave beans for the removal of selected heavy metals were very high. This provide us to use Fava beans as a low coast adsorbent material to clean up the water in the environment from toxic heavy metals such as $\mathrm{Pb}(\mathrm{II})$, Cd(II) and Zn(II) ions.

\section{Keywords}

Adsorption Capacity; Heavy Metals; Adsorbent; Wastewater Treatment; Fava Beans

\section{Introduction}

Water pollution by heavy metals has been a major concern for chemists and environmental engineers. Nowadays, the industrial and domestic wastewater if not properly managed is responsible for severe damage to the environment and adversely affecting the health of people. Heavy metals spread by industrial wastewater to the surrounding area causing serious problems and injuring living organisms. The most important characteristic that distinguishes heavy metals from other pollutants is their non-biodegradability and their unfavorable tendency to accumulate in living organisms. Due to their wide industrial applications, heavy metals have caused various dis- 
eases and disorder for many living organisms [1] [2]. In many countries, the levels of industrial pollution have been steadily rising, and the pollution problem of industrial wastewater is becoming more serious in the world. Therefore, the treatment of polluted industrial wastewater remains a topic of global concern. At least 20 metals are classified as toxic and half of these are emitted into the environment in quantities that pose risk to humans health [3] [4].

Different technologies have been used for the removal of heavy metals from wastewater. They mainly include: precipitation, ion exchange, membrane processes, evaporation, chemical oxidation or reduction, solvent extraction and biological materials. These techniques are very expensive and economically unfavorable or technically complicated, and are used only in special cases of wastewater treatment [5] [6].

Relatively a new green technology for the treatment of industrial wastewater was adsorption of heavy metals and dyes from aqueous solutions by using natural material. Adsorption process has been proved to be an excellent way to treat industrial waste effluents, offering significant advantages like the low cost, availability, profitability, easy operation, and efficiency [7]-[9]. In addition, adsorbent of heavy metal could be selective for some metal ions [10].

In the present work, the Fava beans were used as adsorbent material for removal of $\mathrm{Pb}(\mathrm{II}), \mathrm{Cd}(\mathrm{II}) \mathrm{and} \mathrm{Zn}(\mathrm{II})$ ions from aqueous solutions and wastewater samples. Fava beans are one of the oldest plants under cultivation, and they are eaten in ancient Greece and Rome. Despite the name, fava beans are a member of the pea family, though they are also known as broad beans, pigeon beans, horse beans, and windsor beans. They are popular in Mediterranean cuisine, with many summer dishes celebrating the seasonal bean, although they are also dried for winter use. Fava beans have a distinct flavor and creamy texture that makes them a great addition to a wide variety of dishes [11].

\section{Materials and Methods}

Fava beans were collected from different areas in Tripoli and washed several times with tap water, then by distilled water and allowed to dry in oven at $80^{\circ} \mathrm{C}-100^{\circ} \mathrm{C}$ for $36-48 \mathrm{~h}$. The samples were ground in mortar and passed through 250 - $500 \mathrm{~m}$ standard sieves. Then, the powder was washed with distilled water and dried in an oven at $60^{\circ} \mathrm{C}$ for $6 \mathrm{~h}$. It was kept in plastic-stopper bottle (containers).

The standard solutions of metal ion were prepared as following: The stock solution of lead and cadmium (1000 mg/L) were provided from BDH Company. The working standard solutions were prepared by diluting $100 \mathrm{ml}$ of the stock standard solution of the selected ion to one liter with distilled water (or by diluting 50ml of stock standard solution of selected ion to half liter with distilled water).

A $5 \mathrm{ml}$ of this solution was diluted to $50 \mathrm{ml}$ with distilled water to get a solution contains $10 \mathrm{mg} / \mathrm{l}$ selected ion. These concentrations were used through experiments, $\mathrm{pH}$ of solution was adjusted using $0.1 \mathrm{M} \mathrm{HCl}$ or $0.1 \mathrm{M}$ $\mathrm{NaOH}$, Fresh dilutions. All the adsorption experiments were carried out at room temperature.

The stock solution of Zinc was prepared by dissolving $45.5 \mathrm{~g}$ of zinc powder in volumetric flask to one liter with distilled water.

EDTA standard solution was prepared by drying an amount of EDTA in an oven at $80^{\circ} \mathrm{C}$ then dissolving (264grams) of the dried EDTA in a $100 \mathrm{ml}$ volumetric flask to the mark by distilled water.

The concentrations at equilibrium, $\mathrm{C}_{\mathrm{e}}$ of $\mathrm{Pb}(\mathrm{II})$ and $\mathrm{Cd}(\mathrm{II})$ were determined using atomic absorption spectrophotometer. The concentration was determined after calibrating the instrument with standards within the con-

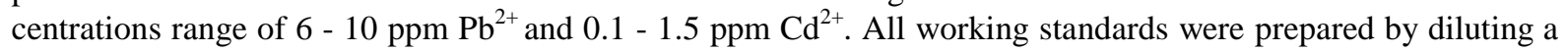
stock solution containing $1000 \mathrm{ppm}$ metal ions. The following analysis wave lengths were used for metal studies $\mathrm{Pb}^{2+} 217 \mathrm{~nm}$ and $\mathrm{Cd}^{2+} 228.8 \mathrm{~nm}$. The analytical grade standards were used to calibrate the instrument which was checked periodically throughout the analysis for it's response. The correlation coefficients for the calibration curves were 0.998 and 1.00 for $\mathrm{Pb}^{2+}$ and $\mathrm{Cd}^{2+}$ respectively, but $\mathrm{Zn}^{2+}$ was determined by compleximetric titration.

\section{Results and Discussion}

\subsection{Effect of Initial pH}

According to several authors [10]-[13], pH has been reported as one of the major parameters controlling the adsorption capacity of metals onto adsorbents because it affects the solubility of the metal ions, the degree of the ionization of the adsorbent during reaction and concentration of the counter of the functional groups of the adsorbent. The higher adsorption capacities were attained at $\mathrm{pH} 3.0$ for $\mathrm{Pb}(\mathrm{II}), \mathrm{pH} 4.5$ for $\mathrm{Cd}(\mathrm{II})$ and $\mathrm{pH} 4$ for $\mathrm{Zn}$ (II) 
ions as shown in Figures 1-3. Table 1 showed the effect of pH value on the adsorption capacity of $\mathrm{Pb}(\mathrm{II}), \mathrm{Cd}(\mathrm{II})$ and $\mathrm{Zn}(\mathrm{II})$ ions onto Fava beans. The adsorption capacity of $\mathrm{Pb}(\mathrm{II}), \mathrm{Cd}(\mathrm{II})$ and $\mathrm{Zn}(\mathrm{II})$ ions onto Fava beans was increased as the $\mathrm{pH}$ increased till the optimum $\mathrm{pH}$, after that the $\mathrm{pH}$ decreased, this happened because for the adsorption sites and solubility product for every metalion.

\subsection{Effect of Contact Time}

The contact time is one the effective factors in batch adsorption process and it is essential to evaluate the effect of contact time required to reach equilibrium. It is clear from Figures 4-6 that, the adsorption capacity of $\mathrm{Pb}(\mathrm{II})$, $\mathrm{Cd}(\mathrm{II})$ and $\mathrm{Zn}$ (II) ions by Fava beans increases as the contact time increases and reached the equilibrium state. The conical flasks were shaken for 1:30h at $175 \mathrm{rpm}$ using mechanical shaker for (15, 30, 45, 60, 75, $90 \mathrm{~min})$ are shown in Table 2, then the filtrate was analyzed for $\mathrm{Pb}(\mathrm{II})$ and $\mathrm{Cd}(\mathrm{II})$ by flame AAS and by compleximetric titration for Zn against EDTA.

\subsection{Effect of Adsorbent Quantity}

The effect of adsorbent amount on metal ion adsorption was studied by preparing ( $50 \mathrm{ml}$ of $10 \mathrm{ppm}$ ) solutions of $\mathrm{Pb}(\mathrm{II})$ and $\mathrm{Cd}(\mathrm{II})$ containing different doses adsorbent (0.1,0.3,0.5,0.7,1.0 and 2.0 gram),as shown in Table 3, after shaking the solutions were filtered and the filtrates were analyzed by using(AAS) and \% removal efficiency was calculated for each case. Zn analyzed by compleximetric titration against EDTA. The effect of adsorbent quantity on the adsorbent capacity of $\mathrm{Pb}(\mathrm{II}), \mathrm{Cd}(\mathrm{II})$ and $\mathrm{Zn}(\mathrm{II})$ is shown in Figures 7-9.

\subsection{Effect of Initial Metal Concentration}

The effect of metal concentration was studied by adding $0.5 \mathrm{~g}$ of Fava beans to $50 \mathrm{ml}$ of heavy metal concentra-

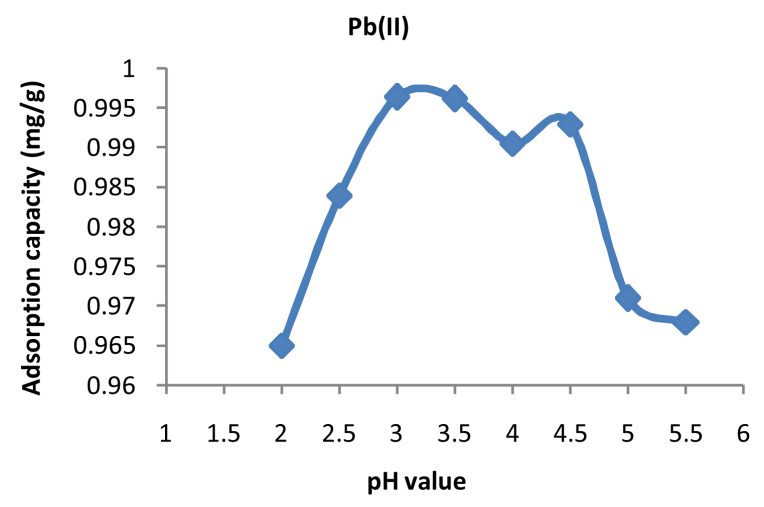

Figure 1. Effect of Initial $\mathrm{pH}$ on the adsorption capacity of $\mathrm{Pb}(\mathrm{II})$ ions onto Fava beans.

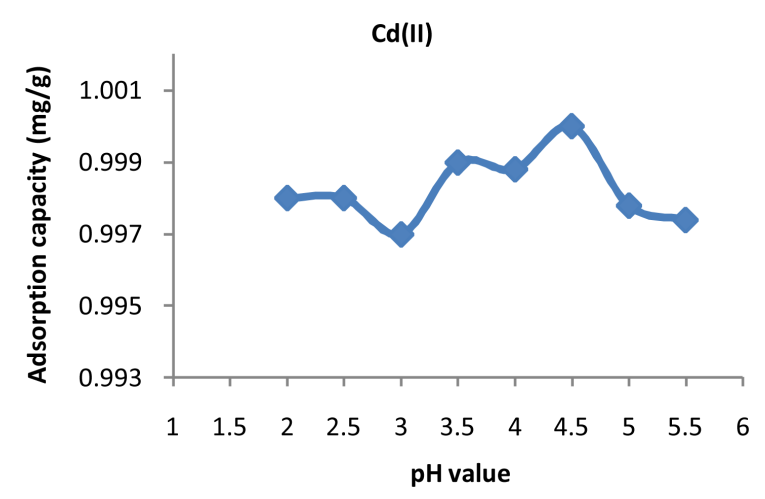

Figure 2. Effect of Initial $\mathrm{pH}$ on the adsorption capacity of Cd(II) ions onto Fava beans. 
$\mathrm{Zn}(\mathrm{II})$

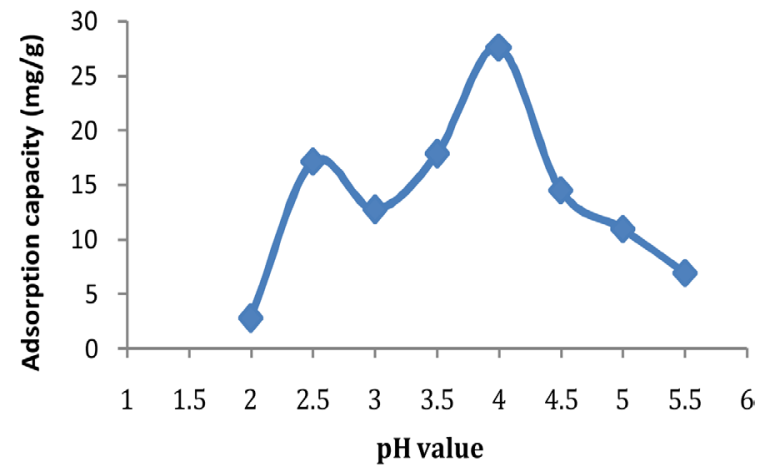

Figure 3. Effect of Initial $\mathrm{pH}$ on the adsorption capacity of $\mathrm{Zn}(\mathrm{II})$ ions onto Fava beans.

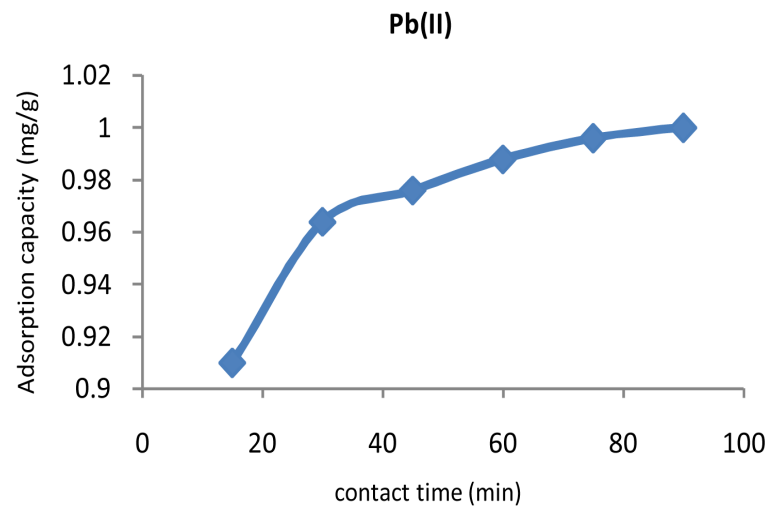

Figure 4. Effect of contact time on the adsorption capacity of $\mathrm{Pb}(\mathrm{II})$ ions onto Fava beans.

Table 1. Effect of initial $\mathrm{pH}$ on the adsorption capacity of $\mathrm{Pb}(\mathrm{II}), \mathrm{Cd}(\mathrm{II})$ and $\mathrm{Zn}(\mathrm{II})$ ions onto Fava beans.

\begin{tabular}{cccc}
\hline & & $\mathrm{q}(\mathrm{mg} / \mathrm{g})$ & \\
\cline { 2 - 4 } Initial $\mathrm{pH}$ & $\mathrm{Pb}(\mathrm{II})$ & $\mathrm{Cd}(\mathrm{II})$ & $\mathrm{Zn}(\mathrm{II})$ \\
& & 0.998 & 2.794 \\
2 & 0.965 & 0.998 & 17.146 \\
2.5 & 0.984 & 0.997 & 12.750 \\
3 & 0.9964 & 0.999 & 17.842 \\
4.5 & 0.9962 & 0.9988 & 27.580 \\
4.5 & 0.9905 & 1.000 & 14.537 \\
5 & 0.993 & 0.9978 & 10.999 \\
5.5 & 0.971 & 0.9974 & 6.9750
\end{tabular}

Table 2. Effect of contact time on the adsorption capacity of $\mathrm{Pb}(\mathrm{II}), \mathrm{Cd}(\mathrm{II})$ and $\mathrm{Zn}(\mathrm{II})$ ions by Fava beans.

\begin{tabular}{cccc}
\hline & & q(mg/g) & Cd(II) \\
\cline { 2 - 4 } Contact time (min) & $\mathrm{Pb}(\mathrm{II})$ & 0.735 & 0.184 \\
15 & 0.910 & 0.768 & 0.836 \\
30 & 0.964 & 0.808 & 2.140 \\
45 & 0.976 & 0.821 & 3.450 \\
70 & 0.988 & 0.895 & 4.751 \\
90 & 0.996 & 0.903 & 5.403 \\
\hline
\end{tabular}


Cd(II)

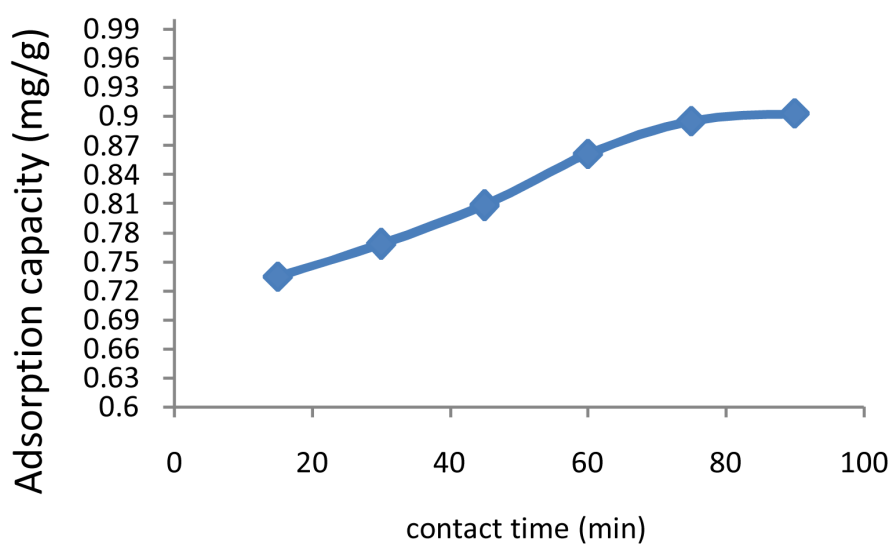

Figure 5. Effect of contact time on the adsorption capacity of $\mathrm{Pb}(\mathrm{II})$ ions onto Fava beans.

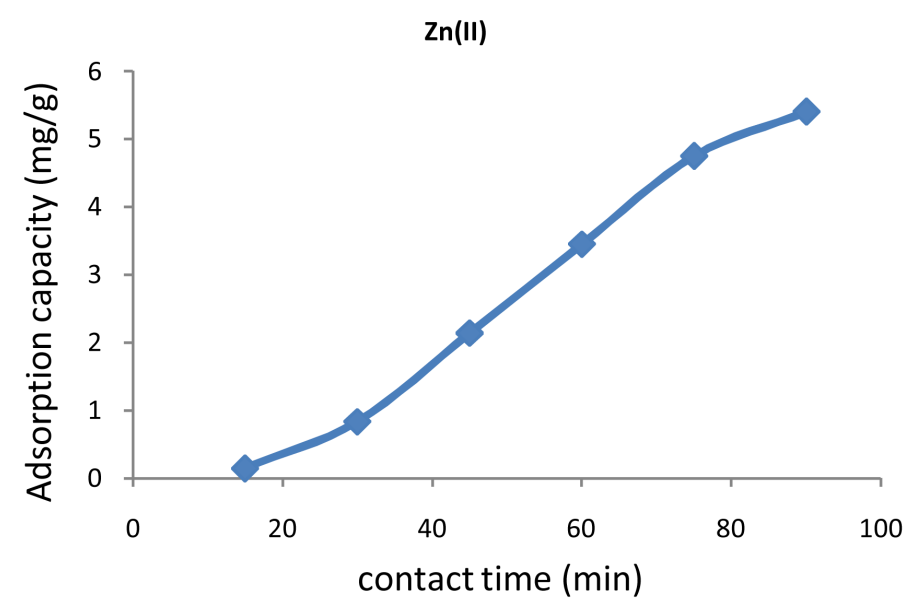

Figure 6. Effect of contact time on the adsorption capacity of Zn(II) ions onto Fava beans.

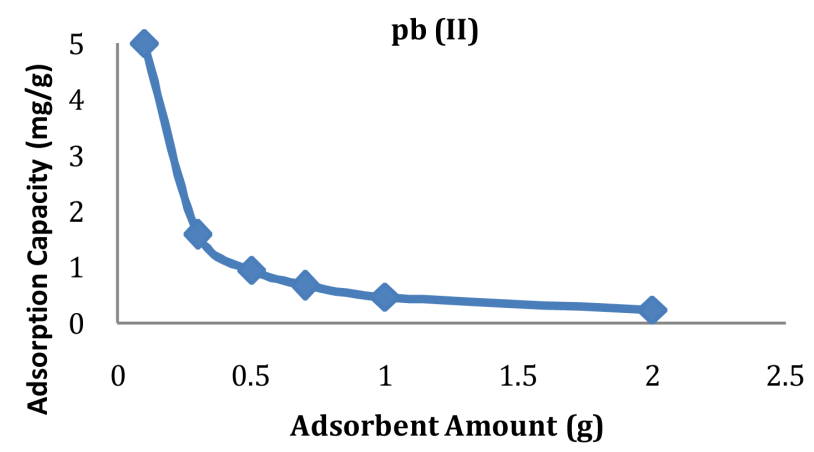

Figure 7. Effect of Adsorbent amount on the adsorption capacity of $\mathrm{Pb}(\mathrm{II})$ ions onto Fava beans.

tions of (5 ppm, $10 \mathrm{ppm}, 15 \mathrm{ppm}, 50 \mathrm{ppm}, 100 \mathrm{ppm}$ ) at $\mathrm{pH}=3.0$ for $\mathrm{Pb}(\mathrm{II})$ and $\mathrm{pH} 4.0$ for $\mathrm{Cd}(\mathrm{II})$ as shown in Table 4. The conical flasks were shaken for 1:30h at $175 \mathrm{rpm}$ using electrical shaker and the filtrate analyzed by using AAS and by titration of various concentrations (10, 20, 30, 40, 50 ppm) of Zn solutions with EDTA. Figures 10-12 show that, the effect of metal ion concentration on adsorption capacity of $\mathrm{Pb}(\mathrm{II}), \mathrm{Cd}(\mathrm{II})$ 
Table 3. Effect of adsorbent quantity on the adsorbent capacity of $\mathrm{Pb}(\mathrm{II}), \mathrm{Cd}(\mathrm{II})$ and $\mathrm{Zn}(\mathrm{II})$ ions by Fava beans.

\begin{tabular}{cccc}
\hline \multirow{2}{*}{ Adsorbent quantity (g) } & & $\mathrm{q}(\mathrm{mg} / \mathrm{g})$ & $\mathrm{Zn}(\mathrm{II})$ \\
\cline { 2 - 3 } & $\mathrm{Pb}(\mathrm{II})$ & $\mathrm{Cd}(\mathrm{II})$ & 71.55 \\
0.1 & 5.000 & 3.917 & 26.15 \\
0.5 & 1.588 & 1.539 & 16.71 \\
0.7 & 0.951 & 0.929 & 12.43 \\
1.0 & 0.678 & 0.661 & 9.220 \\
2.0 & 0.474 & 0.462 & 4.500 \\
\hline
\end{tabular}

Table 4. Effect of metal ion concentration on the adsorption capacity of Pb(II),Cd(II)and Zn(II) ions by Fava beans..

\begin{tabular}{cccc}
\hline \multirow{2}{*}{ Metal concentration $(\mathrm{ppm})$} & & $\mathrm{q}(\mathrm{mg} / \mathrm{g})$ & $\mathrm{Cd}(\mathrm{II})$ \\
\cline { 2 - 4 } & $\mathrm{Pb}(\mathrm{II})$ & 0.492 & 0.868 \\
10 & 0.500 & 0.903 & 1.670 \\
15 & 0.9195 & 1.349 & 2.406 \\
50 & 1.376 & 4.227 & 3.142 \\
100 & 5.000 & 7.976 & 3.812 \\
\hline
\end{tabular}

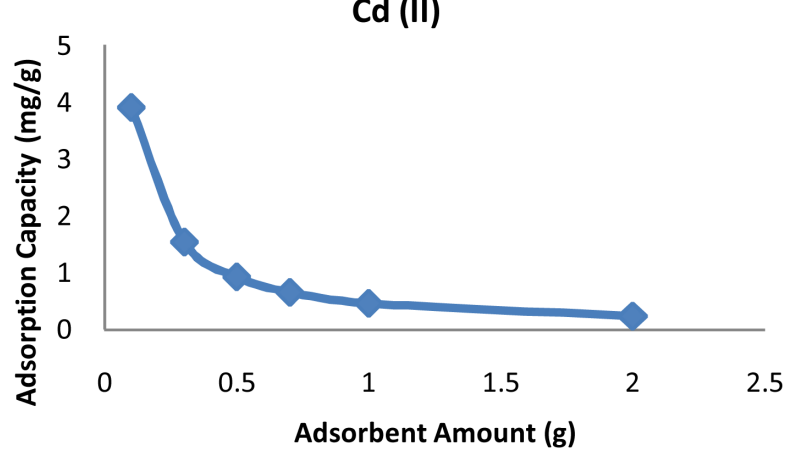

Figure 8. Effect of Adsorbent amount on the adsorption capacity of Cd(II) ions onto Fava beans.

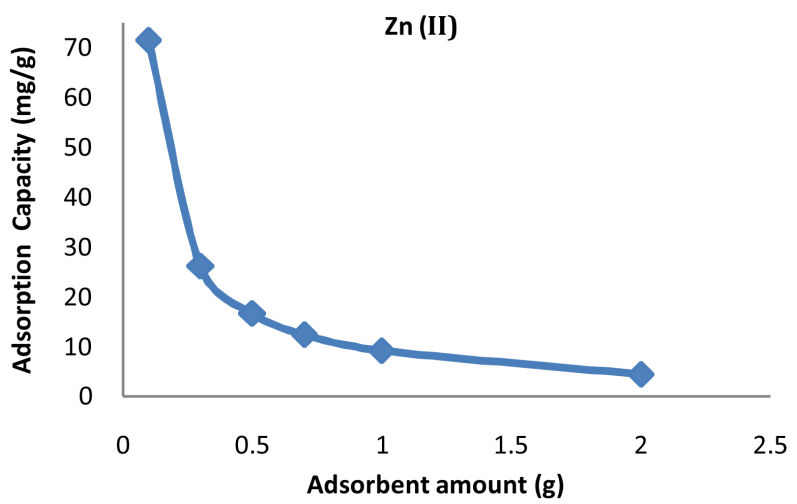

Figure 9. Effect of Adsorbent amount on the adsorption capacity of $\mathrm{Zn}(\mathrm{II})$ ions onto Fava beans.

and $\mathrm{Zn}(\mathrm{II})$ ions by Fava beans. It was resulted that, the adsorption capacity of $\mathrm{Pb}(\mathrm{II}), \mathrm{Cd}(\mathrm{II}) \mathrm{and} \mathrm{Zn}$ (II) ions onto Fava beans increased with increase in initial concentration of metal ions. It means that the adsorption is highly dependent on initial concentration of metal ions. This is because at lower concentration, the ratio of initial num ber of metal ions to the available surface area is low, subsequently the fractional adsorption sites become independent of initial concentration. However, at high concentration the available sites of adsorption becomes 
pb (II)

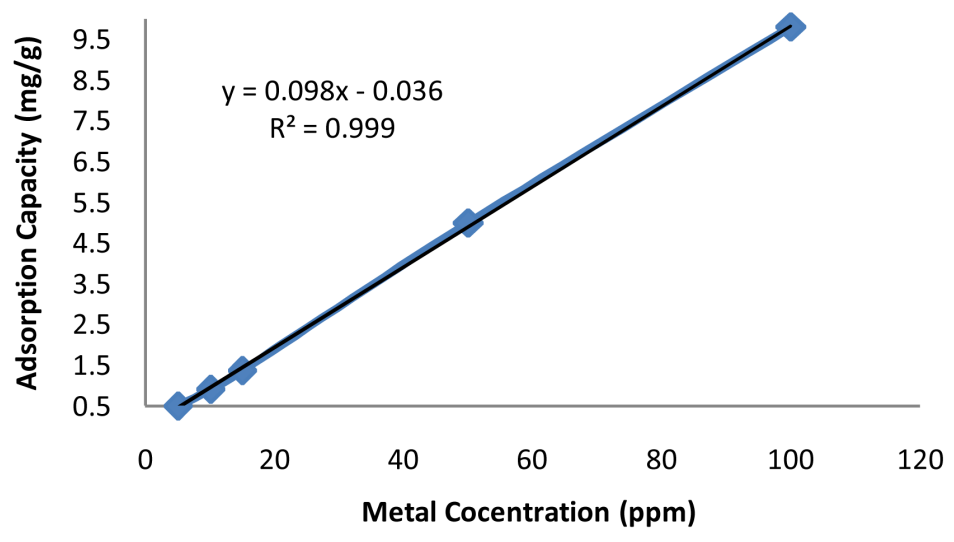

Figure 10. Effect of Metal concentration on the adsorption capacity of $\mathrm{Pb}(\mathrm{II})$ ions onto Fava beans.

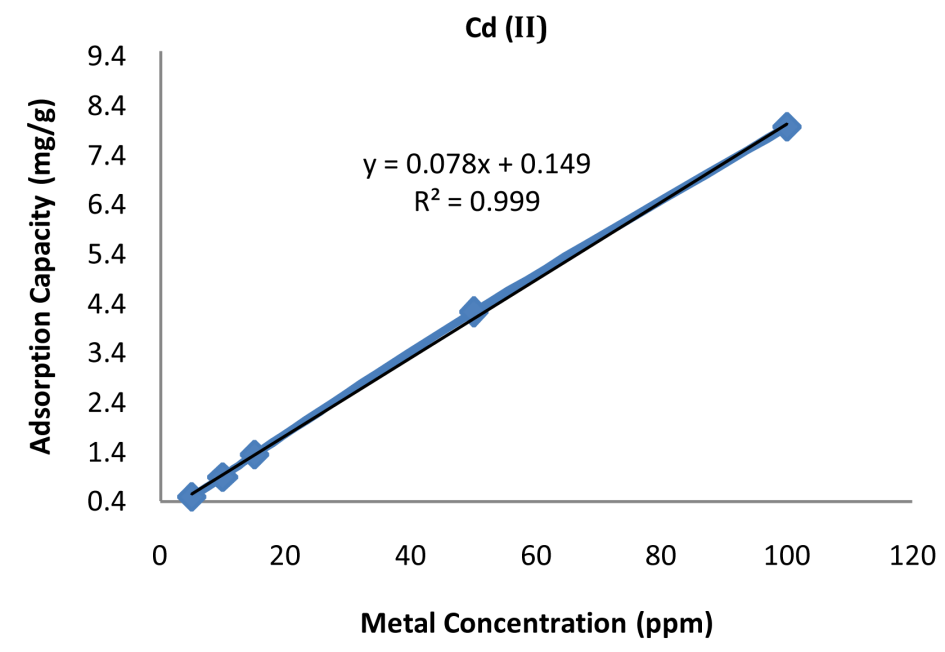

Figure 11. Effect of metal concentration on the adsorption capacity of Cd(II) ions onto Fava beans.

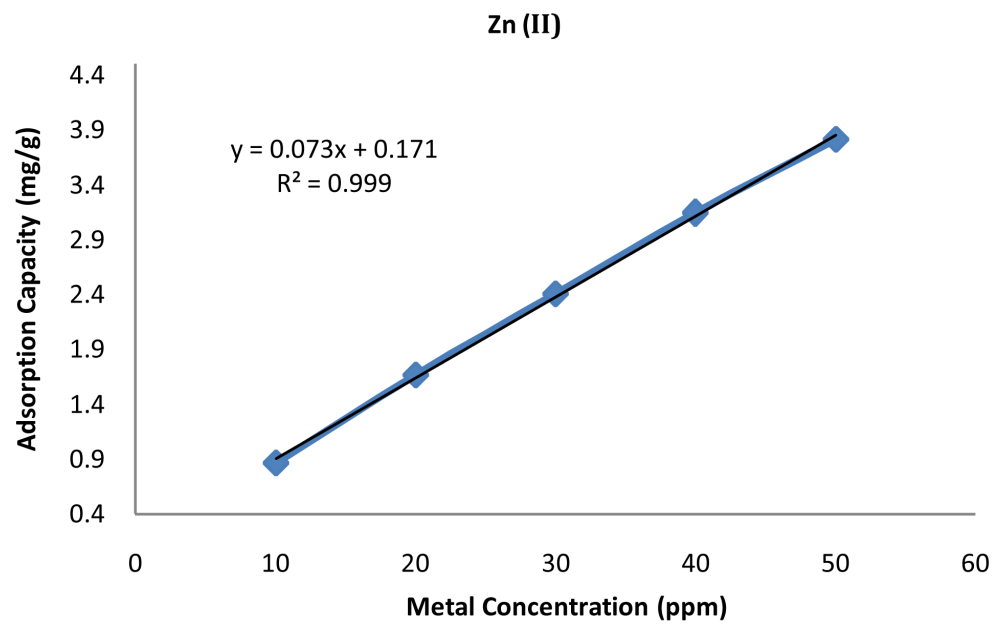

Figure 12. Effect of metal concentration on the adsorption capacity of $\mathrm{Zn}$ (II) ions onto Fava beans. 
fewer and hence the adsorption of metal ions is dependent upon initial concentration [12].

\subsection{Langmuir Adsorption Isotherm}

The Langmuir adsorption isotherm is the best known linear model for monolayer adsorption and most frequently utilized to determine the adsorption parameters. The Langmuir isotherms are based on these assumptions Langmuir [13]. The linear form of the Langmuir equation is giving:

$$
q=\frac{\mathrm{KlCe}}{1+\mathrm{alCe}}
$$

where $q(\mathrm{mg} / \mathrm{g})$ is the amount of metal ions adsorbed onto the unit mass of the adsorbent to form a complete monolayer on the surface. $K_{L}$ is the Langmuir equilibrium constant which is related to the affinity of binding sites; Ce the solution phase metal ion concentration, and $\alpha_{L}$ is the Langmuir constant. The constants $K_{L}$ and $\alpha_{L}$ are the characteristics of the Langmuir equation and can be determined from linearized form of the Langmuir equation .The plots of $C_{e} / q$ against $C e$ are presented in Figures 13-15 for adsorption of $\mathrm{Pb}(\mathrm{II}), \mathrm{Cd}(\mathrm{II})$ and $\mathrm{Zn}(\mathrm{II})$ ions onto Fava beans at room temperature.

\subsection{Removal of Lead from Battery Manufacturing Wastewater by Fava Beans (Real Sample)}

In accordance with the results obtained previously the procedure was applied to wastewater, employing Fava beans as the removing material. The real sample was taken from batteries factory sited in Tajora (Tripoli,

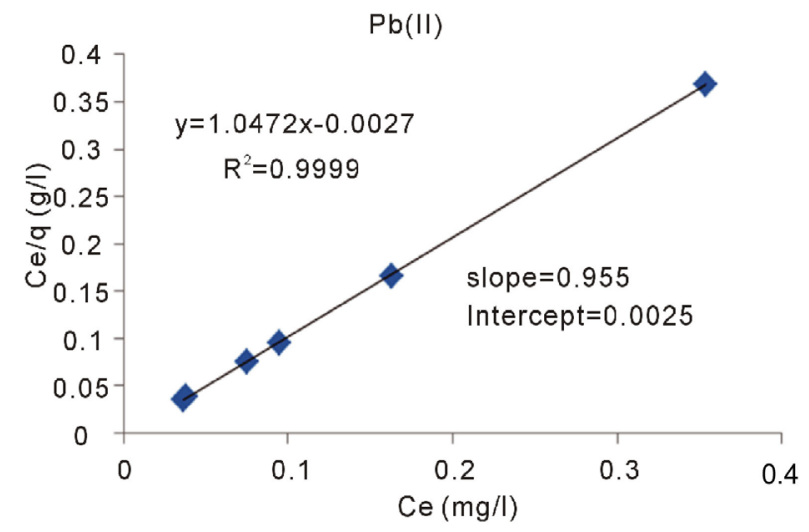

Figure 13. Langmuir adsorption isotherm of $\mathrm{Pb}(\mathrm{II})$ ions onto Fava beans at room temperature.

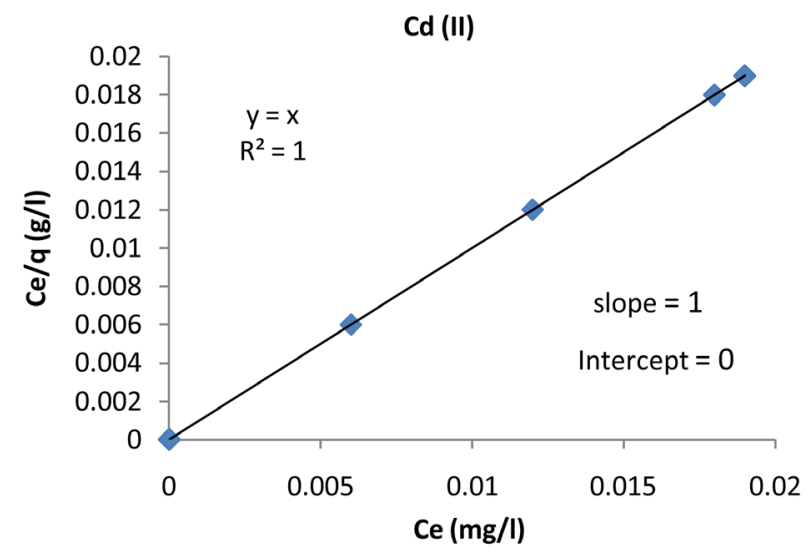

Figure 14. Langmuir adsorption isotherm of Cd(II) ions onto Fava beans at room temperature. 


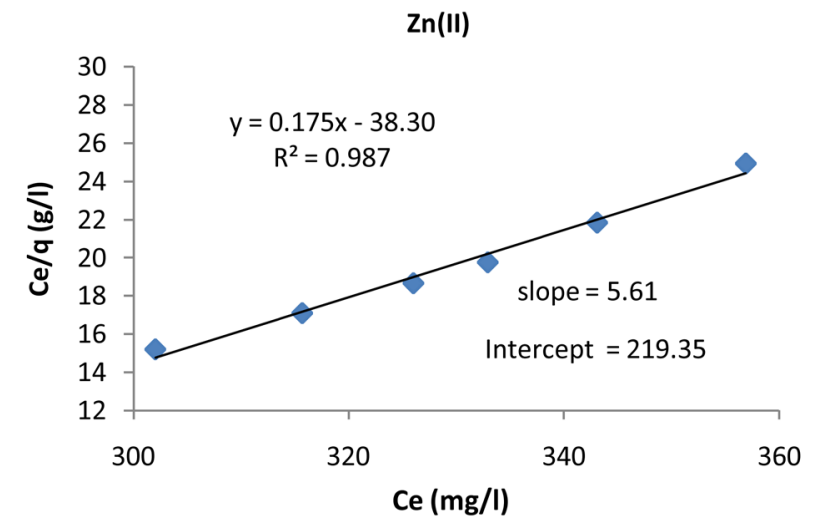

Figure 15. Langmuir adsorption isotherm of $\mathrm{Zn}(\mathrm{II})$ ions onto Fava beans at room temperature.

Libya). Several steps are involved in the electroplating process. One of them, the wash after the electrolytic bath, and the efficiency of this step have repercussion in the quality of the final product and the electrolytic bath composition. For the control of this composition, the purity of the water used in the cleaning processes is necessary, and high volumes of water are used. This water must be therefore treated by a depuration system before it is recovered or removed, although the concentration of corresponding metallic ion is relatively low. Real sample of wastewater was taken from inside batteries factory. This sample was treated under the best conditions to remove $\mathrm{Pb}(\mathrm{II})$, where $\mathrm{pH}=3.0$, contact time was $1: 30 \mathrm{~h}$ and adsorbent concentration was $0.5 \mathrm{~g}$. The results which obtained by A.A.S as the following:

\begin{tabular}{ccc}
\hline $\mathrm{C}_{\mathrm{o}}$ & $\mathrm{Ce}$ & $\mathrm{RSD}$ \\
\hline $9.13 \mathrm{ppm}$ & $1.003 \mathrm{ppm}$ & 0.0385 \\
\hline
\end{tabular}

$$
\text { Removale percent }(\mathrm{P} \%)=\frac{19.3-1.003}{19.3} \times 100=89.014 \%
$$

\section{Conclusion}

In this work, experiments were studied under laboratory conditions. From the experimental data of adsorption of $\mathrm{Pb}(\mathrm{II})$, $\mathrm{Cd}(\mathrm{II})$ and $\mathrm{Zn}$ (II) ions onto Fava beans powder surface, the following points can be concluded, the adsorption capacity of metal ions was found dependent on initial $\mathrm{pH}$, contact time, adsorbent amount and metal concentration of heavy metal. The obtained maximum adsorption capacity of Fava beans for removal of selected heavy metals was $100 \%$ for $\mathrm{Pb}(\mathrm{II}), 92.86 \%$ for $\mathrm{Cd}(\mathrm{II})$ and 36.86 for $\mathrm{Zn}(\mathrm{II})$ at $2 \mathrm{~g}$ dose amount of Fava beans powder. The experimental results for all target metal ions were fitted very well to Langmuir mathematical equation.

\section{References}

[1] Kirk, P.W.W. and Lester, J.N. (1984) Significance and Behavior of Heavy Metals in Wastewater Treatment Process. Science of the Total Environment, 40, 1-44. http://dx.doi.org/10.1016/0048-9697(84)90340-1

[2] Orhan Ardali, Y. (1990) The Removal of Heavy Metals from Plating Wastewater. M. Sc Thesis, Ondokuz Mayis University, Sam Sun.

[3] Dwari, R.K., Biswas, M.N. and Meikap, B.C. (2004) Performance Characteristics for Particles of Sand-FCC and FlyAsh in a Novel Hydrocyclone. Chemical Engineering Science, 59, 671-684. http://dx.doi.org/10.1016/j.ces.2003.11.015

[4] Park, S. and Jung, W.Y. (2001) Removal of Chromium by Activated Carbon Fibers Plate with Copper Metal. Carbon, 2, 15-21.

[5] Abdel-Halim, S.H., Shehata, A.M.A. and El-Shahat, M.F. (2003) Removal of Lead Ion from Industrial Wastewater by Different Types of Natural Materials. Water Research, 37, 1678-1683. 
http://dx.doi.org/10.1016/S0043-1354(02)00554-7

[6] Qadeer, R. and Akhtar, S. (2005) Study of Lead Ion Adsorption of Active Carbon. Turkish Journal of Chemistry, 29, 95-99.

[7] Amuda, O.S., Giwa, A.A. and Bello, I.A. (2007) Removal of Heavy Metal from Industrial Wastewater Using Modified Activated Coconut Shell Carbon. Biochemical Engineering Journal, 36, 174-181. http://dx.doi.org/10.1016/j.bej.2007.02.013

[8] Guptaa, S. and Babua, B.V. (2006) Adsorption of Cr(VI) by a Low-Cost Adsorbent Prepared from Neem Leaves. Proceeding of National Conference on Environmental Conservation, Pilani, 175-180.

[9] Shin, E.W. and Rowell, R.M. (2005) Cadmium Ion Sorption onto Lignocellulosic Biosorbent Modified by Sulfonation: The Origin of Sorption Capacity Improvement. Chemosphere, 60, 1054-1061. http://dx.doi.org/10.1016/j.chemosphere.2005.01.017

[10] Hashem, M.A. (2007) Adsorption of Lead Ion from Aqueous Solution by Okra Wastes. International Journal of Physical Science, 2, 178-184.

[11] Hashem, A., Hussein, H.A., Sanousi, M.A., Saad, E.E. and Khouda, M.M. (2007) Calligonum Comosum as a Novel Bio-Adsorbent Material for Removal of Hg(II) from Aqueous Solution. Energy Education and Technology, 19, 93-109.

[12] Badmus, M.A.O., Audu, T.O.K. and Anyata, B.U. (2007) Removal of Lead Ion from Industrial Wastewater by Activated Carbon Prepared from Periwinkle Shells (Typanotonus fuscatus). Turkish Journal of Engineering and Environmental Sciences, 31, 251-263.

[13] Karri, S.K., Saper, R.B. and Kales, S.N. (2008) Lead Encephalopathy Due to Traditional Medicines. Current Drug Safety, 3, 54-59. http://dx.doi.org/10.2174/157488608783333907 